\title{
Socioeconomic Disadvantage Increases Risk of Prevalent and Persistent Depression in Later Life
}

Osvaldo P. Almeida, ${ }^{1,2,3}$ Jane Pirkis, ${ }^{4}$ Ngaire Kerse,${ }^{5}$ Moira Sim,${ }^{6}$ Leon Flicker,,${ }^{2,7,8}$ John Snowdon, ${ }^{9}$ Brian Draper, ${ }^{10}$ Gerard Byrne, ${ }^{11}$ Nicola T. Lautenschlager, ${ }^{1,2,12}$ Nigel Stocks, ${ }^{13}$ Helman Alfonso, ${ }^{1,2}$ Jon J. Pfaff ${ }^{1,2}$

1 School of Psychiatry \& Clinical Neurosciences, University of Western Australia

2 Western Australian Centre for Health \& Ageing, Centre for Medical Research, University of Western Australia

3 Department of Psychiatry, Royal Perth Hospital

4 School of Population Health, University of Melbourne

5 School of Population Health, University of Auckland

${ }^{6}$ School of Medical Sciences, Edith Cowan University

7 School of Medicine and Pharmacology, University of Western Australia

8 Department of Geriatric Medicine, Royal Perth Hospital

y Discipline of Psychiatry, Sydney Medical School, University of Sydney

${ }^{10}$ School of Psychiatry, University of New South Wales

${ }^{11}$ School of Medicine, University of Queensland

${ }^{12}$ Academic Unit for Psychiatry of Old Age, St Vincent's Health, Department of Psychiatry, University of Melbourne

${ }^{13}$ Discipline of General Practice, University of Adelaide

Word-count: 4555 (excluding references and tables)

Author Contributions: Almeida had full access to all the data in the study and takes responsibility for the integrity of the data and the accuracy of the data analysis.

Study concept and design: Almeida.

Acquisition of data: Almeida, Pfaff, Pirkis, Kerse, Sim, Draper, Snowdon, Goldney, Flicker, Lautenschlager, Stocks.

Analysis of data: Alfonso and Almeida performed all analyses.

Drafting of the manuscript: Almeida.

Critical revision of the manuscript for important intellectual content: All authors.

Financial Disclosures: No disclosures to report.

Funding/Support: The study was supported by the project grant number 353569 from the National Health and Medical Research Council of Australia (NHMRC) to Almeida, Pfaff, Kerse, Pirkis, Goldney and Snowdon, and by an infrastructure grant from beyondblue Australia.

Role of the Sponsors: The sponsors had no role in the design and conduct of the study; collection, management, analysis, and interpretation of the data; or preparation, review, or approval of the manuscript.

Acknowledgements: The investigators thank participants and research staff for their generous contribution.

\section{Correspondence}

Prof. Osvaldo P. Almeida, WA Centre for Health \& Ageing (M573), University of Western Australia, 35 Stirling Highway, Crawley, Perth, WA 6009, Australia. Email: osvaldo.almeida@uwa.edu.au. 


\section{ABSTRACT}

\section{Background}

Depression is more frequent in socioeconomically disadvantaged than affluent neighbourhoods, but this association may be due to confounding. This study aimed to determine the independent association between socioeconomic disadvantage and depression.

\section{Methods}

We recruited 21417 older adults via their general practitioners (GPs) and used the Patient Health Questionnaire (PHQ-9) to assess clinically significant depression (PHQ-9 $\geq 10$ ) and major depressive symptoms. We divided the Index of Relative Socioeconomic Disadvantage into quintiles. Other measures included age, gender, place of birth, marital status, physical activity, smoking, alcohol use, height and weight, living arrangements, early life adversity, financial strain, number of medical conditions, and education of treating GPs about depression and self-harm behaviour. After 2 years participants completed the PHQ-9 and reported their use of antidepressants and health services.

\section{$\underline{\text { Results }}$}

Depression affected $6 \%$ and $10 \%$ of participants in the least and the most disadvantaged quintiles. The proportion of participants with major depressive symptoms was $2 \%$ and $4 \%$. The adjusted odds of depression and major depression were 1.4 (95\% confidence interval, $95 \% \mathrm{Cl}=1.1-1.6)$ and $1.8(95 \% \mathrm{Cl}=1.3-2.5)$ for the most disadvantaged. The adjusted odds of persistent major depression were $2.4(95 \% \mathrm{Cl}=1.3-4.5)$ for the most disadvantaged group. There was no association between disadvantage and service use. Antidepressant use was greatest in the most disadvantaged groups.

\section{$\underline{\text { Conclusions }}$}

The higher prevalence and persistence of depression amongst disadvantaged older adults cannot be easily explained by confounding. Management of depression in disadvantaged areas may need to extend beyond traditional medical and psychological approaches.

\section{$\underline{\text { Key-words }}$}

Socioeconomic disadvantage, poverty, mood disorder, depression, elderly, aged, lifestyle, adversity. 


\section{INTRODUCTION}

Depression is a common and disabling disorder that affects people of all ages and cultures (Lopez et al., 2006). About $10 \%$ of adults over the age of 60 years living in the community show evidence of depression (Pirkis et al., 2009), which is associated with increased morbidity and mortality (Almeida et al., 2011a). Over recent years, numerous attempts have been made to clarify the causes of depression in later life, with some researchers suggesting that symptoms arise because of increased cerebrovascular burden (Alexopoulos et al., 1997), whilst others have emphasised the importance of structural brain abnormalities (Almeida et al., 2003; O'Brien et al., 2004), biochemical imbalances (Almeida et al., 2009; Dantzer et al., 2008), physical frailty (Krishnan et al., 2002), childhood adversity (Draper et al., 2008), and psychosocial stresses (Murphy, 1982).

Older people who reside in neighbourhoods characterised by low socioeconomic status have more depressive symptoms than people living in more affluent areas (Aneshensel et al., 2007; Wight et al., 2009), and there is concern that this may be due, at least in part, to barriers hindering their access to health care (Kirby and Kaneda, 2006). However, it is unclear if the link between socioeconomic disadvantage and depression can be adequately explained by suboptimal access to services (Kubzansky et al., 2005), or if this association is a downstream product of a lifelong history of health and socioeconomic hazards.

Almeida and colleagues developed a probabilistic model of depression that takes into account demographic, lifestyle, health and psychosocial factors (Almeida et al., 2011b). They showed that these factors interact with each other and that even remote events, such as childhood adversity, contribute to modulation of the risk of depression in later life. Their model implies that early life adversity may hinder development, cause psychological stress, limit access to education and, consequently, to skilled work. It may also facilitate the adoption of hazardous lifestyle practices (such as smoking, excessive alcohol consumption, unhealthy diet, physical inactivity, strained relationships), which in turn could contribute to the development of obesity, hypertension and diabetes, thereby increasing the risk of health events (such as cardiovascular events and some cancers) and frailty (Almeida, 2011). Such a cascade of events may explain why symptoms of 
depression seem more prevalent amongst older adults living in socioeconomically disadvantaged neighbourhoods, as their place of abode may reflect a history of difficulties that started well before older age.

In order to decrease the prevalence of depression in later life, we need to understand its causes, and use this information to guide the design and implementation of preventive strategies (Almeida, 2011). When considering the possible role of socioeconomic disadvantage, we should clarify if its relationship with depression is driven by proximal or remote factors, and if its contribution is independent of other known variables. In addition, we should seek to determine the consequences of socioeconomic disadvantage on the long term outcome of depression, as this may indicate the need to remediate prevalent factors that perpetuate the presence of symptoms (secondary prevention).

We designed this study to clarify the association between socioeconomic status and depression in later life. We hypothesised that socioeconomic disadvantage would be associated with depression, but that this association would be explained by demographic, lifestyle, social and health variables. In addition, we hypothesised that socioeconomic disadvantage would be associated with greater persistence of depressive symptoms over 2 years and lower use of primary care and mental health services.

\section{METHODS}

\section{Study design}

The present report involves two interrelated studies. The first had a cross-sectional design that investigated the association between an index of socioeconomic disadvantage and prevalent depression. The second involved a 2-year follow up assessment of depression and of health service use based on data collected as part of the DEPS-GP study, an open label, parallel, randomised trial that allocated general practitioners (GPs) to a targeted and non-targeted educational intervention about depression and self-harm behaviour (Almeida et al., 2011c; Williamson et al., 2007). 
The Ethics Committees of the University of Western Australia, the University of Melbourne and the Royal Australian College of General Practitioners approved the study protocol and all participants provided informed consent. The study was conducted in accordance to the declaration of Helsinki.

\section{Participants}

We posted a single study invitation to 19046 GPs listed on the Australasian Medical Publishing Company Proprietary Limited database and practicing in the Australian states of Western Australia, South Australia, Victoria, New South Wales and Queensland. The accuracy and completeness of this list is unknown. Seven hundred and seventy-two practitioners replied to our invitation and 373 agreed to recruit adults aged 60 years or over for the study. Details about the recruitment process have been described elsewhere (Almeida et al., 2011c). Briefly, a total of 77000 invitations together with the study questionnaire and a reply paid envelope were sent out to all patients aged 60 years or over under the care of participating GPs (average of 203 patients per practitioner): 42384 did not respond. In addition, 9087 participants declined to participate, 2934 were returned as 'not known at this address', 411 did not meet the inclusion criteria (age < 60 years or not reported), and a further 767 people were excluded because of incomplete information on depressive symptoms or because linkage to the index of relative socioeconomic disadvantage was not possible, leaving a total study sample of 21417 adults aged 60 years or over. We started recruitment in July 2005 and completed the collection of endpoints in June 2008.

\section{$\underline{\text { Study measures }}$}

The primary outcome of interest of this study was the presence of clinically significant depressive symptoms, as assessed by the Primary Health Questionnaire (PHQ-9) (Kroenke et al., 2001). The PHQ-9 consists of nine items that assess the presence of depressive symptoms, with each receiving a score that can range from 0 (not at all) to 3 (nearly every day). A total score of 10 or more indicates the presence of clinically significant depressive symptoms (Arroll et al., 2010). In 
addition, we used a validated algorithm based on PHQ-9 ratings to determine the presence of a major depressive episode according to DSM-IV criteria (Spitzer et al., 1999).

The principal exposure of the study was the Index of Relative Socio-Economic Disadvantage (IRSED), which is a component of the Socio-Economic Indexes for Areas (SEIFA) of Australia (Pink, 2008). The IRSED takes into account the following characteristics of dwellings in a certain geographical postcode area: the proportion of occupied dwellings with connection to the internet, the proportion of employed people classified as 'labourers', the proportion of people aged 15 years and over with no post-school qualifications, the proportion of people with stated annual household equivalised income between $\$ 13,000$ and $\$ 20,799$ (approximately 2 nd and 3rd deciles), the proportion of households renting from government or community organisations, the proportion of people in the labour force that are unemployed, the proportion of one parent families with dependent offspring, the proportion of households paying rent less than $\$ 120$ per week, the proportion of people under 70 years who have a long-term health condition or disability and need assistance, the proportion of occupied dwellings with no car, the proportion of people who identify themselves as Aboriginal, the proportion of occupied dwellings requiring one or more extra bedrooms, the proportion of people aged 15 years or over who are separated or divorced, the proportion of people classified as machinery operators and drivers, the proportion of people aged 15 years and over who did not go to school, the proportion of people classified as low skill community and personal service workers, and the proportion of people who do not speak English well. This information is then used to produce rankings. For the purposes of this study, we divided the IRSED into quintiles, with lower quintiles indicating greater socio-economic disadvantage (Pink, 2008). We also obtained data from the Australian Bureau of Statistics to determine the degree of 'remoteness' of households (Pink, 2010), as geographic isolation could represent an additional barrier for participants to access services.

In addition, we asked participants to record the date of their assessment and their date of birth, which we then used to calculate their age. They also provided information about their gender (male/female), place of birth (Australia/other), educational achievement (completed/did not 
complete tertiary education), marital status (married-de facto/other), physical activity (at least 30 minutes of moderate or vigorous physical activity five or more days per week: yes/no), smoking (never/past/current), and alcohol use (no use, non-risk alcohol use, or risk alcohol use defined by 4 or more standard drinks per day nearly every day or 6 or more standard drinks on any one day). We used self-reported information on weight and height to calculate the body mass index (BMI; $\mathrm{Kg} / \mathrm{m}^{2}$ ). Participants also provided information on living arrangements (alone/with others) and completed the Duke Social Support Index (DSSI) subjective support subscale, which yields a measure of perceived social support - lower scores indicate decreasing perceived support (Koenig et al., 1993). Of note, we split the final question of the DSSI (satisfaction of relationships with family or friends) into two separate items: satisfaction of relationships with family and satisfaction of relationships with friends. DSSI scores $\leq 31$ represented the lowest quartile of scores in our sample and were used as an indicator of low social support. We also asked participants whether they had been victims of physical or sexual abuse before they were aged 15 years (yes/no), and whether they were experiencing financial strains at the time of assessment (not at all or a little compared with distinctly or definitely). Lastly, participants rated their overall health (fair/poor compared with good to excellent) and the presence of any of the following conditions: arthritis, diabetes, hypertension, stroke, coronary heart disease, congestive heart failure, peripheral arterial disease, asthma or chronic bronchitis, emphysema, osteoporosis, cancer (except skin cancer), dementia, thyroid disorders, and traumatic brain injury. We grouped participants according to the number of self-reported morbidities: 0,1 to 5 and 6 or more. We grouped morbidities this way for 2 reasons: (1) to ensure that the number of participants in each cell was sufficiently large to produce a precise effect estimate, (2) because preliminary analysis showed that the association between number of morbidities with depression increased more noticeably after 5 morbidities.

After 24 months participants received a similar questionnaire by post, which collected information about the presence of depressive symptoms using the PHQ-9 (Kroenke et al., 2001). We used the same procedures described above to determine the presence of clinically significant depressive symptoms and of a major depressive episode. At the 24-month assessment we also asked participants how often they had visited their GP during the preceding 12 months, and if they had 
been reviewed by a psychiatrist (yes/no) or another mental health professional during that same period (yes/no). Finally, we asked participants to list all medications they had used during the past 2 weeks and whether they had used an antidepressant during the preceding 12 months (yes/no).

\section{Procedures for the collection of study measures}

Consenting participants completed a self-rating questionnaire designed to assess items of interest, which was then returned to our research office using the reply paid envelope provided. After 24 months they received a similar questionnaire by post, which collected information about the presence of depressive symptoms and about health service use. Between the baseline and 24month assessment, the GPs of participants were randomly assigned to a control group or to an educational intervention that consisted of 3 components: (1) printed educational material about the assessment and management of depression and self-harm behaviour in later life, (2) detailed feedback of up to 20 practice audits, and (3) educational newsletters posted 6, 12 and 18 months after randomisation. The control group did not receive educational material nor did they receive detailed individualised feedback for their practice audits. The results of the trial have been reported in detail elsewhere (Almeida et al., 2011c): the intervention with GPs did not change the prevalence of depression amongst their patients, but it decreased the prevalence of suicide ideation (these were the primary endpoints of the intervention).

\section{$\underline{\text { Statistical analyses }}$}

The data were managed and analysed with Stata version 11.1 (StataCorp, College Station, Texas). We used descriptive statistics to summarize the data, cross-tabulation to determine their distribution according to IRSED quintiles (Pearson's chi-square statistic: $x^{2}$ ), and the Cuzick's test for trend to determine the association between measured factors and IRSED quintiles. We then used logistic regression to determine the odds ratio (OR) of the association between IRSED quintiles and the two depression outcomes: clinically significant depression $(P H Q \geq 10)$ and major depressive episode. These models were adjusted, in turn, for demographic, lifestyle, social, health variables and remoteness of abode, and ultimately the best fit model was estimated using the backwards approach to remove variables. The final parsimonious model retained all variables 
associated with $\mathrm{p}$-values $<0.1$ as well as variables that changed the adjusted pseudo $\mathrm{R}$-square by more than $10 \%$ when we attempted to remove them. As education and marital status are integral components of the IRSED, these variables were not included in the multivariate models. We then used the 'predict' command of Stata to estimate the probability of clinically significant depression and of major depressive symptoms according to IRSED as a continuous variable, and plotted the results in a linear spline construction with 3 knots and a quadratic fit.

We subsequently created 4 groups based on the presence of clinically significant depression or major depression at the baseline and 24-month assessments: non-case/non-case, non-case/case, case/non-case and case/case. Our initial analyses took into account the effect of clustering by GP, but this was later dropped because it proved to be negligible (intraclass correlation coefficient $\leq$ 0.01). In addition, our analyses took into account the assignment of GPs to education / usual care to ensure that the outcome of this study was not affected by systematic bias, even though the intervention had no effect on the prevalence of depression amongst participants (Almeida et al., 2011c). We used multinomial logistic regression to estimate the OR of depression at least once (either at baseline or 24 months) compared with neither (non-case/non-case) according to IRSED quintiles, and adjusted these analyses for the participation of GPs in the intervention, as well as for other relevant demographic, lifestyle, social and health variables of participants, as described above. Lastly, we added to the model the number of visits to GP, as this could potentially affect recognition and treatment of depression amongst our participants.

Finally, we used multinomial logistic regression to estimate the OR of visits to GP during the 12 months before the 24-month assessment according to IRSED quintiles, and logistic regression to estimate the OR of contact with psychiatrists and mental health professionals, as well as the use of antidepressants during that time according to IRSED quintiles.

\section{RESULTS}

The mean age of the 21417 participants was 71.9 years (standard deviation=7.7; range=60-101), and $58.8 \%$ were women. Their demographic, lifestyle, social and health characteristics are 
summarised in table 1 according to quintiles of IRSED. Cuzick's test for trend showed an increasing number of Australia-born people in the most disadvantaged quintiles $(z=9.95, p<0.001)$, as well as greater physical inactivity $(z=2.47, p=0.013)$, smoking $(z=5.92, p<0.001)$, and overweight/obesity $(z=7.81, p<0.001)$. Living alone was also increasingly more common in the most disadvantaged quintiles $(z=3.25, p=0.001)$, as was physical $(z=2.37, p=0.018)$ and sexual abuse $(z=2.60, p=0.009)$, and financial strain $(z=5.98, p<0.001)$. Fair or poor self-perceived health became more common with increasing disadvantage $(z=10.31, p<0.001)$, as did the number of comorbidities $(z=8.81, p<0.001)$, the presence of clinically significant depressive symptoms $(z=5.70, p<0.001)$ and of major depression $(z=5.16, p<0.001)$.

\section{TABLE 1}

Table 2 shows the results of logistic regression models used to estimate the OR of clinically significant depression and of major depression according to IRSED quintiles (highest IRSED quintile used as reference: least disadvantaged). Once the contribution of confounding was taken into account in a parsimonious model, only the most disadvantaged group showed an increase in the odds of clinically significant depression $(\mathrm{OR}=1.36,95 \% \mathrm{Cl}=1.12-1.65)$. These associations did not change when the analyses were further adjusted for 'remoteness' of the households (i.e., distance from neighbours, shops and other facilities). The odds of major depression increased with increasing socioeconomic disadvantage, reaching a maximum OR of $1.84(95 \% \mathrm{Cl}=1.35-2.52)$ for people in the most disadvantaged quintile. Figure 1 shows the probability of clinically significant depression (panel A) and major depressive symptoms (panel B) according to the IRSED. The probability of both clinically significant and major depression increased as the IRSED decreased, as did the $95 \%$ confidence limits of the probability estimates.

\section{TABLE 2}

FIGURE 1 
We then grouped participants according to their depression status at the baseline and the 24month assessments and determined the odds of their classification according to IRSED quintiles. The results of these analyses appear in table 3. Two-year outcome data showed that $89 \%$ and $95 \%$ of participants remained free of clinically significant depressive symptoms and major depression. One percent of participants showed evidence of major depressive symptoms at baseline and again after 2 years, 1.7\% had major depressive symptoms at baseline but not follow up, and $2 \%$ were free of major depressive symptoms at baseline but not at follow up. The odds of persisting major depression (i.e., case at baseline and at 24 months) increased progressively with relative socioeconomic disadvantage, reaching a maximum of $2.43(95 \% \mathrm{Cl}=1.32-4.48)$ for participants in the most compared with the least disadvantaged quintile group. These results did not change substantially when the number of visits to GPs during the year that preceded the 24month assessment was taken into account in the analysis (Table 3). Of the 17428 participants for whom data was available at the 24-month follow up assessment, 467 presented major depressive symptoms at baseline (all but one had PHQ-9 score $\geq 10$ ). Of these, 178 continued to fulfil the study criteria for major depressive symptoms at the 24-month assessment. Another 121 (25.9\%) of those who had major depressive symptoms at baseline continued to show evidence of clinically significant depression, but no major depression, after 24 months. Fifty-four of these 121 participants (44.6\%) were in the two most disadvantaged IRSED quintiles ( $p>0.05)$.

\section{TABLE 3}

\section{TABLE 4}

Finally, we investigated whether the 12-month use of health services that participants reported at their 24-months assessment varied according to IRSED quintiles (Table 4). People in the 2nd least disadvantaged and in the most disadvantaged groups visited their GPs more frequently than those in the least disadvantaged quintile group, although such an excess was no longer apparent once medical morbidities were taken into account in the analyses. Compared with people in the least disadvantaged quintile, all other groups reported greater use of antidepressant medications. 


\section{DISCUSSION}

The results of this study show that socioeconomic disadvantage increases the odds of depression in later life and that this association cannot be entirely attributed to demographic or lifestyle factors, social isolation, or comorbid illnesses. We also found that the odds of persistent major depressive symptoms after 2 years were more than twice as large amongst people in the two most disadvantaged groups compared with the least disadvantaged, and that this association could not be adequately explained by the use of antidepressants or health services. Before discussing the meaning and implications of these results, we wish to acknowledge the limitations of our study design.

\section{Limitations}

Our findings are based on data that originated from an intervention trial with general practitioners, and this limits our ability to infer a causal relationship between socioeconomic disadvantage and depression. We are also unable to dismiss the possibility of reverse causality (i.e., depression causing socioeconomic disadvantage), although the results of previous longitudinal studies suggest this would be an improbable direction of the relationship between these variables (Chandola et al., 2003; Glymour et al., 2010; Murphy et al., 1991; Ross, 2000). In addition, participants self-selected to take part in this study, which raises uncertainty about the external validity of the findings and about a possible healthy volunteer bias. Such a bias would have led to a lower prevalence of depression in the sample and would have decreased our ability to adjust our results for confounding due to comorbidity. However, as previously reported (Pirkis et al., 2009), the prevalence of depression in this sample is similar to that of epidemiological surveys that used different methodologies to recruit participants, and the distribution of gender, marital status and schooling of participants is largely consistent with data from the Australian census of 2006 (recruitment took place between 2005 and 2007). Furthermore, the results of this study may have been confounded by unmeasured factors, such as neurocognitive disorders that are common in this age group. We attempted to adjust our analysis for the number of comorbidities reported by participants (including dementia and stroke), but concede that this is unlikely to have dealt with this 
type of counfounding in a satisfactory manner (e.g., Parkinson's disease may be associated with both depression and progressive socioeconomic disadvantage).

We acknowledge that the diagnoses of clinically significant depression and of major depressive symptoms were based on assessment by self-report and not on gold standard structured clinical interviews. Others have shown that the approach that we used is valid (Arroll et al., 2010; Kroenke et al., 2001; Spitzer et al., 1999) and, as previously discussed, our prevalence estimates of depression are consistent with those of other surveys that used well accepted strategies to define 'caseness' (Pirkis et al., 2009).

The study measure of socioeconomic disadvantage was based on the systematic assessment of census data within a certain geographic area, but may not be an accurate reflection of individual participants' socioeconomic status. Wealthy city and country areas are generally socioeconomically homogeneous, as the cost of living in those areas makes them unaffordable for those who are less well off. In contrast, less advantaged areas can be more socioeconomically diverse, and this may partly explain the greater variability in the probability of depression associated with socioeconomic disadvantage that we observed in our study (Figure 1). Nonetheless, we would contend that the approach we used to measure socioeconomic disadvantage is appropriate because existing evidence suggests that exposure to deprived neighbourhoods is associated with poor mental health outcomes regardless of the socioeconomic status of the individual (Stafford et al., 2008a).

The assessment of lifestyle, social and health variables was also based on self-report, although data from other studies suggest this approach has acceptable face validity (Bowlin et al., 1996; Elley et al., 2003; Jamrozik et al., 2011; Koenig et al., 1993). In addition, missing data for specific exposures (e.g., self-reported stroke, financial strain, childhood sexual abuse) may have decreased our ability to adjust the analyses for the effect of confounding, particularly because participants with the relevant exposure may have been more reluctant to volunteer information. In 
this instance, the effect of socioeconomic disadvantage on depression would probably be less pronounced.

\section{$\underline{\text { Interpretation of findings }}$}

Our results suggest that socioeconomic disadvantage increases the risk of depressive symptoms in later life or, alternatively, that high socioeconomic status decreases such a risk. We have also found that the association between socioeconomic disadvantage and depression is particularly robust for prevalent and persistent major depression, which is the most severe end of the spectrum of symptoms. This association cannot be easily attributed to confounding, and the outcomes of previous studies are consistent with the possibility that relative disadvantage is an independent cause of depression (Chandola et al., 2003). Data from the Whitehall II survey showed that residents of deprived or fragmented neighbourhoods had lower mental component summary (MCS) scores, and that longer exposure to such environments had an incremental negative effect on the mental health of participants (Stafford et al., 2008b). In addition, current evidence suggests that perceived neighbourhood disorder facilitates the development of depressive symptoms in young (Ross, 2000) and older adults (Kubzansky et al., 2005). Hence, disadvantage may represent an additional source of stress for people at risk. We have previously shown that physiological and environmental stressors interact to modulate the risk of depression in older age (Almeida et al., 2011b), and it seems that a person's ability to handle stress without developing depressive symptoms is partly mediated by their genetic makeup (Almeida, 2011; Almeida et al., 2009; Caspi et al., 2003). In other words, some older adults may be better equipped than others to negotiate successfully the demands of socioeconomic and neighbourhood disadvantage, and this may be another explanation for the greater variability in the probability of depression that we observed amongst older people living in the most disadvantaged areas of Australia.

The 'inverse care law', outlined by Hart in the 1970s, proposed that access and use of health services is driven by market forces, being optimal in rich and restricted in poor areas (Hart, 1971). In this case, people with depression living in disadvantaged areas would have suboptimal access to primary care and specialist mental health services, thereby leading to the persistence (and 
increasing the prevalence of) depressive episodes. We found that older Australians living in socioeconomically disadvantaged areas had greater persistence of depressive symptoms (particularly major depression) over 24 months compared with their most affluent counterparts. However, there was no evidence that the groups differed in their access and use of primary care and mental health services, although we cannot be certain that the quality of care provided was comparable. Like us, Kubzansky and colleagues noticed that the prevalence of depressive symptoms was greatest amongst older people living in poor neighbourhoods, and reported that access to health services played no obvious role in neighbourhood variations of depressive symptoms (Kubzansky et al., 2005). These results suggest that the higher prevalence of depression that we observed amongst older adults living in socioeconomically disadvantaged areas cannot be easily attributed to limited access to health services.

We also found that the use of antidepressants increased with our measure of socioeconomic disadvantage (i.e., the use of antidepressants was greatest in the most disadvantaged groups). It is possible that medical practitioners favour the use of antidepressants to manage socioeconomically disadvantaged older adults, but it is also possible that older disadvantaged people with depression respond less well to treatment. A secondary analysis of two open label clinical trials of older persons with depression treated with nortriptyline or paroxetine combined with interpersonal psychotherapy showed that residents of low-income areas had a less favourable course of depression and response to treatment (Cohen et al., 2006). These results suggest that the successful management of older adults with depression living in disadvantaged areas may need to extend beyond the traditional medical and psychological approach to treatment.

In conclusion, we found that the higher prevalence and persistence of major depressive symptoms amongst older adults living in socioeconomically disadvantaged areas cannot be entirely explained by demographic, lifestyle, social and health factors, or by restricted access to services. These results suggest that the needs of older people with depression living in disadvantaged areas are not being adequately addressed either because current approaches to care are inadequate or because unmeasured factors in their environment contribute to triggering or perpetuating 
symptoms (or both). Over recent years health professionals have relied increasingly on the prescription of antidepressants to manage depression, even though there is no evidence that this has led to a decline in the prevalence of mood disorders in the community (Mojtabai, 2011). At present, it is unclear if social interventions designed to decrease neighbourhood tension and fragmentation would succeed in reducing the prevalence of depression in later life, although the potential benefits associated with better integrated communities suggest this is a goal worth pursuing. 


\section{REFERENCES}

Alexopoulos, G.S., Meyers, B.S., Young, R.C., Campbell, S., Silbersweig, D., Charlson, M., 1997. 'Vascular depression' hypothesis. Arch Gen Psychiatry 54 (10), 915-922.

Almeida, O.P., 2011. Evolution, depression and the interplay between chance and choices. Int Psychogeriatr 23 (7), 1021-1025.

Almeida, O.P., Alfonso, H., Flicker, L., Hankey, G.J., Norman, P.E., 2011a. Cardiovascular disease, depression and mortality: the Health In Men Study. Am J Geriatr Psychiatry.

Almeida, O.P., Alfonso, H., Pirkis, J., Kerse, N., Sim, M., Flicker, L., Snowdon, J., Draper, B., Byrne, G., Goldney, R., Lautenschlager, N.T., Stocks, N., Scazufca, M., Huisman, M., Araya, R., Pfaff, J., 2011b. A practical approach to assess depression risk and to guide risk reduction strategies in later life. Int Psychogeriatr 23 (2), 280-291.

Almeida, O.P., Burton, E.J., Ferrier, N., McKeith, I.G., O'Brien, J.T., 2003. Depression with late onset is associated with right frontal lobe atrophy. Psychol Med 33 (4), 675-681.

Almeida, O.P., Norman, P.E., Allcock, R., van Bockxmeer, F., Hankey, G.J., Jamrozik, K., Flicker, L., 2009. Polymorphisms of the CRP gene inhibit inflammatory response and increase susceptibility to depression: the Health in Men Study. Int J Epidemiol 38 (4), 1049-1059.

Almeida, O.P., Pirkis, J., Kerse, N., Sim, M., Flicker, L., Snowdon, J., Draper, B., Byrne, G., Goldney, R., Lautenschlager, N., Stocks, N., Alfonso, H., Pfaff, J.J., 2011c. A randomized trial to reduce the prevalence of depression and self-harm behavior in older primary care patients. Ann Fam Med (in press).

Aneshensel, C.S., Wight, R.G., Miller-Martinez, D., Botticello, A.L., Karlamangla, A.S., Seeman, T.E., 2007. Urban neighborhoods and depressive symptoms among older adults. J Gerontol B Psychol Sci Soc Sci 62B (1), S52-59.

Arroll, B., Goodyear-Smith, F., Crengle, S., Gunn, J., Kerse, N., Fishman, T., Falloon, K., Hatcher, S., 2010. Validation of PHQ-2 and PHQ-9 to screen for major depression in the primary care population. 8 (4), 348-353.

Bowlin, S.J., Morrill, B.D., Nafziger, A.N., Lewis, C., Pearson, T.A., 1996. Reliability and changes in validity of self-reported cardiovascular disease risk factors using dual response: the behavioral risk factor survey. J Clin Epidemiol 49 (5), 511-517.

Caspi, A., Sugden, K., Moffitt, T.E., Taylor, A., Craig, I.W., Harrington, H., McClay, J., Mill, J., Martin, J., Braithwaite, A., Poulton, R., 2003. Influence of life stress on depression: moderation by a polymorphism in the 5-HTT gene. Science 301 (5631), 386-389.

Chandola, T., Bartley, M., Sacker, A., Jenkinson, C., Marmot, M., 2003. Health selection in the Whitehall II study, UK. Soc Sci Med 56 (10), 2059-2072.

Cohen, A., Houck, P.R., Szanto, K., Dew, M.A., Gilman, S.E., Reynolds, C.F., 3rd, 2006. Social inequalities in response to antidepressant treatment in older adults. Arch Gen Psychiatry 63 (1), 50-56.

Dantzer, R., O'Connor, J.C., Freund, G.G., Johnson, R.W., Kelley, K.W., 2008. From inflammation to sickness and depression: when the immune system subjugates the brain. Nat Rev Neurosci 9 (1), 46-56.

Draper, B., Pfaff, J.J., Pirkis, J., Snowdon, J., Lautenschlager, N.T., Wilson, I., Almeida, O.P., 2008. Long-term effects of childhood abuse on the quality of life and health of older people: results 
from the Depression and Early Prevention of Suicide in General Practice Project. J Am Geriatr Soc 56 (2), 262-271.

Elley, C.R., Kerse, N.M., Arroll, B., 2003. Why target sedentary adults in primary health care? Baseline results from the Waikato Heart, Health, and Activity Study. Prev Med 37 (4), 342-348.

Glymour, M.M., Mujahid, M., Wu, Q., White, K., Tchetgen Tchetgen, E.J., 2010. Neighborhood disadvantage and self-assessed health, disability, and depressive symptoms: longitudinal results from the health and retirement study. Ann Epidemiol 20 (11), 856-861.

Hart, J.T., 1971. The inverse care law. Lancet 1 (7696), 405-412.

Jamrozik, K., McLaughlin, D., McCaul, K., Almeida, O.P., Wong, K.Y., Vagenas, D., Dobson, A., 2011. Women who smoke like men die like men who smoke: findings from two Australian cohort studies. Tob Control 20 (4), 258-265.

Kirby, J.B., Kaneda, T., 2006. Access to health care: does neighborhood residential instability matter? J Health Soc Behav 47 (2), 142-155.

Koenig, H.G., Westlund, R.E., George, L.K., Hughes, D.C., Blazer, D.G., Hybels, C., 1993. Abbreviating the Duke Social Support Index for use in chronically ill elderly individuals. 34 (1), 61 69.

Krishnan, K.R., Delong, M., Kraemer, H., Carney, R., Spiegel, D., Gordon, C., McDonald, W., Dew, M., Alexopoulos, G., Buckwalter, K., Cohen, P.D., Evans, D., Kaufmann, P.G., Olin, J., Otey, E., Wainscott, C., 2002. Comorbidity of depression with other medical diseases in the elderly. Biol Psychiatry 52 (6), 559-588.

Kroenke, K., Spitzer, R.L., Williams, J.B., 2001. The PHQ-9: validity of a brief depression severity measure. $16(9), 606-613$.

Kubzansky, L.D., Subramanian, S.V., Kawachi, I., Fay, M.E., Soobader, M.J., Berkman, L.F., 2005. Neighborhood contextual influences on depressive symptoms in the elderly. Am J Epidemiol 162 (3), 253-260.

Lopez, A.D., Mathers, C.D., Ezzati, M., Jamison, D.T., Murray, C.J., 2006. Global and regional burden of disease and risk factors, 2001: systematic analysis of population health data. Lancet 367 (9524), 1747-1757.

Mojtabai, R., 2011. The public health impact of antidepressants: An instrumental variable analysis. J Affect Disord.

Murphy, E., 1982. Social origins of depression in old age. Br J Psychiatry 141 135-142.

Murphy, J.M., Olivier, D.C., Monson, R.R., Sobol, A.M., Federman, E.B., Leighton, A.H., 1991. Depression and anxiety in relation to social status. A prospective epidemiologic study. Arch Gen Psychiatry 48 (3), 223-229.

O'Brien, J.T., Lloyd, A., McKeith, I., Gholkar, A., Ferrier, N., 2004. A longitudinal study of hippocampal volume, cortisol levels, and cognition in older depressed subjects. Am J Psychiatry 161 (11), 2081-2090.

Pink, B., 2008. An Introduction to Socio-Economic Indexes for Areas (SEIFA) 2006. Australian Bureau of Statistics, Canberra.

Pink, B., 2010. Australian Standard Geographical Classification (ASGC). Australian Bureau of Statistics, Canberra. 
Pirkis, J., Pfaff, J., Williamson, M., Tyson, O., Stocks, N., Goldney, R., Draper, B., Snowdon, J., Lautenschlager, N., Almeida, O.P., 2009. The community prevalence of depression in older Australians. J Affect Disord 115 (1-2), 54-61.

Ross, C.E., 2000. Neighborhood disadvantage and adult depression. J Health Soc Behav 41 (June), 177-187.

Spitzer, R.L., Kroenke, K., Williams, J.B., 1999. Validation and utility of a self-report version of PRIME-MD: the PHQ primary care study. Primary Care Evaluation of Mental Disorders. Patient Health Questionnaire. Jama 282 (18), 1737-1744.

Stafford, M., Gimeno, D., Marmot, M.G., 2008a. Neighbourhood characteristics and trajectories of health functioning: a multilevel prospective analysis. Eur J Public Health 18 (6), 604-610.

Stafford, M., Gimeno, D., Marmot, M.G., 2008b. Neighbourhood characteristics and trajectories of health functioning: a multilevel prospective analysis. Eur J Public Health 18 (6), 604-610.

Wight, R.G., Cummings, J.R., Karlamangla, A.S., Aneshensel, C.S., 2009. Urban neighborhood context and change in depressive symptoms in late life. J Gerontol B Psychol Sci Soc Sci 64B (2), 247-251.

Williamson, M.K., Pirkis, J., Pfaff, J.J., Tyson, O., Sim, M., Kerse, N., Lautenschlager, N.T., Stocks, N.P., Almeida, O.P., 2007. Recruiting and retaining GPs and patients in intervention studies: the DEPS-GP project as a case study. BMC Med. Res. Methodol. 742. 
Table 1. Distribution of demographic, lifestyle, social and health variables at the time of enrolment into the study according to quintiles of the Index of Relative Socioeconomic Disadvantage (from least to most disadvantaged).

\begin{tabular}{|c|c|c|c|c|c|c|}
\hline & \multicolumn{5}{|c|}{ Relative Socioeconomic Disadvantage } & \multirow[b]{2}{*}{$p^{*}$} \\
\hline & $\begin{array}{c}\text { Least } \\
\mathrm{N}=4203 \\
\mathrm{n}(\%)\end{array}$ & $\begin{array}{c}\text { 2nd Least } \\
\mathrm{N}=4287 \\
\mathrm{n}(\%)\end{array}$ & $\begin{array}{c}\text { Middle } \\
\mathrm{N}=4291 \\
\mathrm{n}(\%)\end{array}$ & $\begin{array}{c}\text { 2nd Most } \\
\mathrm{N}=4348 \\
\mathrm{n}(\%)\end{array}$ & $\begin{array}{c}\text { Most } \\
\mathrm{N}=4288 \\
\mathrm{n}(\%)\end{array}$ & \\
\hline \multicolumn{7}{|l|}{ Demographic variables } \\
\hline Age (in years) & $920(21.9)$ & $893(20.8)$ & $877(20.4)$ & $929(21.4)$ & $781(18.2)$ & $<0.001$ \\
\hline $65-69$ & $1025(24.4)$ & $1042(24.3)$ & $1015(23.6)$ & $1023(23.5)$ & $944(22.0)$ & \\
\hline $70-74$ & $822(19.6)$ & $847(19.8)$ & $902(21.0)$ & $877(20.2)$ & $897(20.9)$ & \\
\hline $75-79$ & $767(18.2)$ & $833(19.4)$ & $845(19.7)$ & $862(19.8)$ & $955(22.3)$ & \\
\hline $80-84$ & $441(10.5)$ & $419(9.8)$ & $429(10.0)$ & $449(10.3)$ & $473(11.0)$ & \\
\hline $85+$ & $228(5.4)$ & $253(5.9)$ & $223(5.2)$ & $208(4.8)$ & $238(5.5)$ & \\
\hline Female gender & $2515(59.9)$ & $2583(60.3)$ & $2449(57.1)$ & $2491(57.3)$ & $2555(59.6)$ & 0.003 \\
\hline Australian born & $2992(71.6)$ & $2974(69.8)$ & $3163(74.3)$ & $3372(77.9)$ & $3332(78.0)$ & $<0.001$ \\
\hline Higher degree education & 1077 (26.2) & $663(15.8)$ & 559 (13.3) & $446(10.5)$ & $330(7.9)$ & $<0.001$ \\
\hline Not married & 1267 (30.3) & $1449(34.0)$ & $1385(32.5)$ & 1419 (32.8) & $1548(36.2)$ & $<0.001$ \\
\hline \multicolumn{7}{|l|}{ Lifestyle } \\
\hline Physically inactive & 1465 (35.3) & 1578 (37.3) & $1578(37.4)$ & 1557 (36.2) & $1644(38.8)$ & 0.016 \\
\hline Smoking & $2310(55.5)$ & $2223(52.6)$ & $2129(50.3)$ & $2184(50.9)$ & $2177(51.4)$ & $<0.001$ \\
\hline Past & $1678(40.3)$ & $1747(41.3)$ & $1810(42.8)$ & $1805(42.0)$ & $1734(40.9)$ & \\
\hline Current & $174(4.2)$ & $256(6.1)$ & $290(6.9)$ & $303(7.1)$ & $323(7.6)$ & \\
\hline Risk alcohol use & $573(14.1)$ & $504(12.2)$ & $626(15.1)$ & $651(15.4)$ & $531(12.9)$ & $<0.001$ \\
\hline Overweight or obese & $2275(58.5)$ & $2503(64.1)$ & $2544(65.4)$ & $2613(66.2)$ & $2586(66.9)$ & $<0.001$ \\
\hline \multicolumn{7}{|l|}{ Social variables } \\
\hline Living alone & $972(23.2)$ & $997(23.4)$ & $1021(24.0)$ & $1069(24.7)$ & $1106(26.0)$ & 0.022 \\
\hline Low social support & $1033(24.8)$ & 1115 (26.2) & $1120(26.3)$ & $1156(26.8)$ & $1062(25.1)$ & 0.164 \\
\hline Early loss of parents & $490(11.8)$ & $569(13.5)$ & $540(12.7)$ & $540(12.6)$ & $579(13.7)$ & 0.073 \\
\hline Early physical abuse & $241(5.8)$ & $273(6.4)$ & $298(7.0)$ & $313(7.3)$ & $289(6.8)$ & 0.060 \\
\hline Early sexual abuse & $239(5.8)$ & $258(6.1)$ & $281(6.6)$ & $313(7.3)$ & $284(6.7)$ & 0.046 \\
\hline Financial strain & $320(7.9)$ & $448(10.9)$ & $452(11.1)$ & $442(10.6)$ & $512(12.6)$ & $<0.001$ \\
\hline
\end{tabular}




\begin{tabular}{|c|c|c|c|c|c|c|}
\hline & \multicolumn{5}{|c|}{ Relative Socioeconomic Disadvantage } & \multirow[b]{2}{*}{$p^{*}$} \\
\hline & $\begin{array}{l}\text { Least } \\
\mathrm{N}=4203 \\
\mathrm{n}(\%)\end{array}$ & $\begin{array}{c}\text { 2nd Least } \\
\mathrm{N}=4287 \\
\mathrm{n}(\%)\end{array}$ & $\begin{array}{c}\text { Middle } \\
\mathrm{N}=4291 \\
\mathrm{n}(\%)\end{array}$ & $\begin{array}{c}\text { 2nd Most } \\
\mathrm{N}=4348 \\
\mathrm{n}(\%)\end{array}$ & $\begin{array}{c}\text { Most } \\
\mathrm{N}=4288 \\
\mathrm{n}(\%)\end{array}$ & \\
\hline \multicolumn{7}{|l|}{ Health variables } \\
\hline Fair/poor health & $726(17.4)$ & $914(21.5)$ & $1021(24.0)$ & $1019(23.6)$ & $1142(26.9)$ & $<0.001$ \\
\hline Comorbidities & $498(11.8)$ & $424(9.9)$ & $377(8.8)$ & $376(8.6)$ & $316(7.4)$ & $<0.001$ \\
\hline $1-5$ & $3509(83.5)$ & $3645(85.0)$ & $3651(85.1)$ & 3706 (85.2) & 3657 (85.3) & \\
\hline $6+$ & $196(4.7)$ & $218(5.1)$ & $263(6.1)$ & $266(6.1)$ & $315(7.3)$ & \\
\hline Clinically depressed & $257(6.1)$ & $329(7.7)$ & $363(8.5)$ & $357(8.2)$ & $411(9.7)$ & $<0.001$ \\
\hline Major depression & $78(1.9)$ & $136(3.2)$ & $149(3.5)$ & $145(3.3)$ & $170(4.0)$ & $<0.001$ \\
\hline
\end{tabular}

${ }^{*} p$-value derived from Pearson's $x^{2}$ statistic. 
Table 2. Odds ratio (OR) of depression at the time of enrolment according to quintiles of the Index of Relative Socioeconomic Disadvantage (from least to most disadvantaged).

\begin{tabular}{|c|c|c|c|c|c|}
\hline & \multicolumn{5}{|c|}{ Relative Socioeconomic Disadvantage } \\
\hline & $\begin{array}{l}\text { Least } \\
\mathrm{N}=4203\end{array}$ & $\begin{array}{l}\text { 2nd Least } \\
\mathrm{N}=4287\end{array}$ & $\begin{array}{l}\text { Middle } \\
\mathrm{N}=4291\end{array}$ & $\begin{array}{l}\text { 2nd Most } \\
\mathrm{N}=4348\end{array}$ & $\begin{array}{c}\text { Most } \\
\mathrm{N}=4288\end{array}$ \\
\hline \multicolumn{6}{|l|}{ Clinical Depression } \\
\hline $\begin{array}{l}\text { OR, Crude } \\
(95 \% \mathrm{Cl})\end{array}$ & $\begin{array}{c}1 \\
\text { [Reference] }\end{array}$ & $\begin{array}{c}1.28 \\
(1.08-1.51)\end{array}$ & $\begin{array}{c}1.42 \\
(1.20-1.68)\end{array}$ & $\begin{array}{c}1.37 \\
(1.16-1.62)\end{array}$ & $\begin{array}{c}1.63 \\
(1.39-1.92)\end{array}$ \\
\hline $\begin{array}{l}\text { OR, adjusted demographic } \\
(95 \% \mathrm{Cl})\end{array}$ & $\begin{array}{c}1 \\
\text { [Reference] }\end{array}$ & $\begin{array}{c}1.27 \\
(1.07-1.51)\end{array}$ & $\begin{array}{c}1.44 \\
(1.22-1.70)\end{array}$ & $\begin{array}{c}1.38 \\
(1.17-1.63)\end{array}$ & $\begin{array}{c}1.67 \\
(1.41-1.96)\end{array}$ \\
\hline $\begin{array}{l}\text { OR, adjusted lifestyle } \\
(95 \% \mathrm{Cl})\end{array}$ & $\begin{array}{c}1 \\
\text { [Reference] }\end{array}$ & $\begin{array}{c}1.25 \\
(1.04-1.51)\end{array}$ & $\begin{array}{c}1.33 \\
(1.11-1.60)\end{array}$ & $\begin{array}{c}1.32 \\
(1.10-1.59)\end{array}$ & $\begin{array}{c}1.54 \\
(1.29-1.85)\end{array}$ \\
\hline $\begin{array}{l}\text { OR, adjusted social } \\
(95 \% \mathrm{Cl})\end{array}$ & $\begin{array}{c}1 \\
\text { [Reference] }\end{array}$ & $\begin{array}{c}1.18 \\
(0.99-1.41)\end{array}$ & $\begin{array}{c}1.34 \\
(1.13-1.60)\end{array}$ & $\begin{array}{c}1.28 \\
(1.08-1.52)\end{array}$ & $\begin{array}{c}1.48 \\
(1.24-1.75)\end{array}$ \\
\hline $\begin{array}{l}\text { OR, adjusted comorbidity } \\
(95 \% \mathrm{Cl})\end{array}$ & $\begin{array}{c}1 \\
\text { [Reference] }\end{array}$ & $\begin{array}{c}1.26 \\
(1.06-1.49)\end{array}$ & $\begin{array}{c}1.36 \\
(1.15-1.61)\end{array}$ & $\begin{array}{c}1.31 \\
(1.11-1.55)\end{array}$ & $\begin{array}{c}1.52 \\
(1.29-1.79)\end{array}$ \\
\hline $\begin{array}{l}\text { OR, best fit model } \\
(95 \% \mathrm{Cl})\end{array}$ & $\begin{array}{c}1 \\
\text { [Reference] }\end{array}$ & $\begin{array}{c}1.09 \\
(0.89-1.32)\end{array}$ & $\begin{array}{c}1.21 \\
(0.99-1.47)\end{array}$ & $\begin{array}{c}1.19 \\
(0.98-1.45)\end{array}$ & $\begin{array}{c}1.36 \\
(1.12-1.65)\end{array}$ \\
\hline \multicolumn{6}{|l|}{ Major Depression } \\
\hline $\begin{array}{l}\text { OR, Crude } \\
(95 \% \mathrm{Cl})\end{array}$ & $\begin{array}{c}1 \\
\text { [Reference] }\end{array}$ & $\begin{array}{c}1.73 \\
(1.31-2.30)\end{array}$ & $\begin{array}{c}1.91 \\
(1.44-2.52)\end{array}$ & $\begin{array}{c}1.83 \\
(1.39-2.43)\end{array}$ & $\begin{array}{c}2.27 \\
(1.73-2.98)\end{array}$ \\
\hline $\begin{array}{l}\text { OR, adjusted demographic } \\
(95 \% \mathrm{Cl})\end{array}$ & $\begin{array}{c}1 \\
\text { [Reference] }\end{array}$ & $\begin{array}{c}1.73 \\
(1.31-2.30)\end{array}$ & $\begin{array}{c}1.92 \\
(1.46-2.54)\end{array}$ & $\begin{array}{c}1.83 \\
(1.39-2.43)\end{array}$ & $\begin{array}{c}2.27 \\
(1.73-2.98)\end{array}$ \\
\hline $\begin{array}{l}\text { OR, adjusted lifestyle } \\
(95 \% \mathrm{Cl})\end{array}$ & $\begin{array}{c}1 \\
\text { [Reference] }\end{array}$ & $\begin{array}{c}1.69 \\
(1.24-2.29)\end{array}$ & $\begin{array}{c}1.66 \\
(1.22-2.26)\end{array}$ & $\begin{array}{c}1.56 \\
(1.14-2.13)\end{array}$ & $\begin{array}{c}2.04 \\
(1.51-2.75)\end{array}$ \\
\hline $\begin{array}{l}\text { OR, adjusted social } \\
(95 \% \mathrm{Cl})\end{array}$ & $\begin{array}{c}1 \\
\text { [Reference] }\end{array}$ & $\begin{array}{c}1.54 \\
(1.15-2.07)\end{array}$ & $\begin{array}{c}1.74 \\
(1.31-2.33)\end{array}$ & $\begin{array}{c}1.70 \\
(1.27-2.26)\end{array}$ & $\begin{array}{c}1.97 \\
(1.48-2.61)\end{array}$ \\
\hline $\begin{array}{l}\text { OR, adjusted comorbidity } \\
(95 \% \mathrm{Cl})\end{array}$ & $\begin{array}{c}1 \\
\text { [Reference] }\end{array}$ & $\begin{array}{c}1.70 \\
(1.28-2.26)\end{array}$ & $\begin{array}{c}1.81 \\
(1.37-2.39)\end{array}$ & $\begin{array}{c}1.73 \\
(1.31-2.29)\end{array}$ & $\begin{array}{c}2.01 \\
(1.53-2.64)\end{array}$ \\
\hline $\begin{array}{l}\text { OR, best fit model }{ }^{\ddagger} \\
(95 \% \mathrm{Cl})\end{array}$ & $\begin{array}{c}1 \\
\text { [Reference] }\end{array}$ & $\begin{array}{c}1.45 \\
(1.05-2.00)\end{array}$ & $\begin{array}{c}1.55 \\
(1.13-2.14)\end{array}$ & $\begin{array}{c}1.48 \\
(1.08-2.04)\end{array}$ & $\begin{array}{c}1.84 \\
(1.35-2.52)\end{array}$ \\
\hline
\end{tabular}

95\% $\mathrm{Cl}$ : $95 \%$ confidence interval of the odds ratio

*The best fit model included the following variables: age, gender, physical inactivity, smoking, overweight/obesity, low social support, childhood sexual abuse, financial strain number of comorbid conditions. They were all associated with $p$ values $<0.1$ in the multivariate model.

${ }^{\ddagger}$ The best fit model included the following variables: age, physical inactivity, smoking, overweight/obesity, living alone, low social support, childhood sexual abuse, financial strain and number of comorbid conditions. They were all associated with $p$-values $<0.1$ in the multivariate model. 
Table 3. Depression outcome of participants according to quintiles of the Index of Relative Socioeconomic Disadvantage (from least to most disadvantaged).

\begin{tabular}{|c|c|c|c|c|c|}
\hline & \multicolumn{5}{|c|}{ Relative Socioeconomic Disadvantage } \\
\hline & $\begin{array}{c}\text { Least } \\
\mathrm{n}(\%) \\
\text { OR }(95 \% \mathrm{Cl})\end{array}$ & $\begin{array}{c}\text { 2nd Least } \\
\text { n (\%) } \\
\text { OR }(95 \% \mathrm{Cl})\end{array}$ & $\begin{array}{c}\text { Middle } \\
\mathrm{n}(\%) \\
\text { OR }(95 \% \mathrm{Cl})\end{array}$ & $\begin{array}{c}\text { 2nd Most } \\
\text { n (\%) } \\
\text { OR }(95 \% \mathrm{Cl})\end{array}$ & $\begin{array}{c}\text { Most } \\
n(\%) \\
\text { OR }(95 \% \mathrm{Cl})\end{array}$ \\
\hline \multicolumn{6}{|c|}{ Clinical Depression at baseline / 24 months } \\
\hline Non-case / Non-case & $\begin{array}{l}3254(91.3) \\
\text { [Reference] }\end{array}$ & $\begin{array}{l}3107(89.4) \\
\text { [Reference] }\end{array}$ & $\begin{array}{l}3100(88.7) \\
\text { [Reference] }\end{array}$ & $\begin{array}{l}3126(88.7) \\
\text { [Reference] }\end{array}$ & $\begin{array}{l}2940(87.3) \\
\text { [Reference] }\end{array}$ \\
\hline Non-case / Case & $\begin{array}{c}111(3.1) \\
\text { [Reference] }\end{array}$ & $\begin{array}{c}148(4.3) \\
1.28(0.97-1.68)\end{array}$ & $\begin{array}{c}146(4.2) \\
1.29(0.98-1.70)\end{array}$ & $\begin{array}{c}153(4.3) \\
1.39(1.06-1.83)\end{array}$ & $\begin{array}{c}153(4.5) \\
1.23(0.93-1.63)\end{array}$ \\
\hline Case / Non-case & $\begin{array}{c}96(2.7) \\
\text { [Reference] }\end{array}$ & $\begin{array}{c}101(2.9) \\
0.89(0.65-1.22)\end{array}$ & $\begin{array}{c}119(3.4) \\
1.05(0.78-1.43)\end{array}$ & $\begin{array}{c}104(2.9) \\
0.97(0.72-1.32)\end{array}$ & $\begin{array}{c}140(4.2) \\
1.23(0.91-1.65)\end{array}$ \\
\hline Case / Case & $\begin{array}{c}103(2.9) \\
\text { [Reference] }\end{array}$ & $\begin{array}{c}120(3.4) \\
1.12(0.82-1.52)\end{array}$ & $\begin{array}{c}131(3.7) \\
1.21(0.89-1.65)\end{array}$ & $\begin{array}{c}143(4.1) \\
1.32(0.98-1.78)\end{array}$ & $\begin{array}{c}133(3.9) \\
1.34(0.99-1.82)\end{array}$ \\
\hline \multicolumn{6}{|c|}{ Major Depression at baseline / 24 months } \\
\hline Non-case / Non-case & $\begin{array}{l}3481(96.9) \\
\text { [Reference] }\end{array}$ & $\begin{array}{l}3332(95.1) \\
\text { [Reference] }\end{array}$ & $\begin{array}{l}3343(94.8) \\
\text { [Reference] }\end{array}$ & $\begin{array}{l}3377 \text { (95.0) } \\
\text { [Reference] }\end{array}$ & $\begin{array}{l}3215(94.7) \\
\text { [Reference] }\end{array}$ \\
\hline Non-case / Case & $\begin{array}{c}49(1.4) \\
\text { [Reference] }\end{array}$ & $\begin{array}{c}81(2.3) \\
1.52(1.02-2.27)\end{array}$ & $\begin{array}{c}75(2.1) \\
1.54(1.03-2.30)\end{array}$ & $\begin{array}{c}77(2.2) \\
1.59(1.07-2.37)\end{array}$ & $\begin{array}{c}70(2.1) \\
1.21(0.79-1.85)\end{array}$ \\
\hline Case / Non-case & $\begin{array}{c}41(1.1) \\
\text { [Reference] }\end{array}$ & $\begin{array}{c}56(1.6) \\
1.34(0.86-2.11)\end{array}$ & $\begin{array}{c}70(2.0) \\
1.65(1.07-2.54)\end{array}$ & $\begin{array}{c}59(1.7) \\
1.25(0.80-1.97)\end{array}$ & $\begin{array}{c}66(1.9) \\
1.54(0.99-2.40)\end{array}$ \\
\hline Case / Case & $\begin{array}{c}20(0.6) \\
\text { [Reference] }\end{array}$ & $\begin{array}{c}35(1.0) \\
1.63(0.86-3.12)\end{array}$ & $\begin{array}{c}37(1.0) \\
1.76(0.93-3.34)\end{array}$ & $\begin{array}{c}42(1.2) \\
2.21(1.19-4.08)^{*}\end{array}$ & $\begin{array}{c}44(1.3) \\
2.43(1.32-4.48)^{\#}\end{array}$ \\
\hline
\end{tabular}

OR $(95 \% \mathrm{Cl})$ : odds ratio (95\% confidence interval of the odds ratio) derived from a multilevel logistic regression model.

Note: the OR reported takes into account the exposure of participants' general practitioners to an educational intervention about depression and self-harm behaviour (no/yes), as well as age, gender, physical inactivity, smoking, overweight/obesity, low social support, childhood sexual abuse, financial strain number of comorbid conditions.

${ }^{*} \mathrm{OR}=2.13(95 \% \mathrm{Cl}=1.15-3.96)$ after adjustment for the measures described above and for the number of visits to GPs in the year before the 24-month assessment.

\#OR=2.28 (95\% $\mathrm{Cl}=1.23-4.21)$ after adjustment for the measures described above and for the number of visits to GPs in the year before the 24-month assessment. 
Table 4. Self-reported contact with health professionals during the year preceding the 24-month assessment of depression according to quintiles of the Index of Relative Socioeconomic Disadvantage.

\begin{tabular}{|c|c|c|c|c|c|c|}
\hline & & \multicolumn{5}{|c|}{ Relative Socioeconomic Disadvantage } \\
\hline & & $\begin{array}{c}\text { Least } \\
\mathrm{n}(\%) \\
\text { OR }(95 \% \mathrm{Cl})\end{array}$ & $\begin{array}{c}\text { 2nd Least } \\
\text { n (\%) } \\
\text { OR }(95 \% \mathrm{Cl})\end{array}$ & $\begin{array}{c}\text { Middle } \\
n(\%) \\
\text { OR }(95 \% \mathrm{Cl})\end{array}$ & $\begin{array}{c}\text { 2nd Most } \\
\text { n (\%) } \\
\text { OR }(95 \% \mathrm{Cl})\end{array}$ & $\begin{array}{c}\text { Most } \\
n(\%) \\
\text { OR }(95 \% \mathrm{Cl})\end{array}$ \\
\hline \multirow[t]{3}{*}{ Visits to GP } & 0 & $\begin{array}{c}32(0.9) \\
\text { [Reference] }\end{array}$ & $\begin{array}{c}19(0.5) \\
\text { [Reference] }\end{array}$ & $\begin{array}{c}28(0.8) \\
\text { [Reference] }\end{array}$ & $\begin{array}{c}31(0.9) \\
\text { [Reference] }\end{array}$ & $\begin{array}{c}20(0.6) \\
\text { [Reference] }\end{array}$ \\
\hline & 1 to 3 & $\begin{array}{l}1155(32.8) \\
\text { [Reference] }\end{array}$ & $\begin{array}{c}956(27.9) \\
1.41(0.79-2.50)\end{array}$ & $\begin{array}{c}1047(30.2) \\
1.06(0.63-1.78)\end{array}$ & $\begin{array}{c}1060(30.4) \\
0.95(0.58-1.58)\end{array}$ & $\begin{array}{c}874(26.3) \\
1.22(0.69-2.15)\end{array}$ \\
\hline & 4 to 6 & $\begin{array}{l}1360(38.6) \\
\text { [Reference] }\end{array}$ & $\begin{array}{c}1368(39.9) \\
1.72(0.97-3.05)\end{array}$ & $\begin{array}{c}1363(39.3) \\
1.20(0.71-2.00)\end{array}$ & $\begin{array}{c}1325(37.9) \\
1.02(0.62-1.68)\end{array}$ & $\begin{array}{c}1298(39.0) \\
1.55(0.88-2.72)\end{array}$ \\
\hline & 7 to 11 & $\begin{array}{c}585(16.6) \\
\text { [Reference] }\end{array}$ & $\begin{array}{c}631(18.4) \\
1.86(1.04-3.31)^{*}\end{array}$ & $\begin{array}{c}626(18.0) \\
1.30(0.77-2.19)\end{array}$ & $\begin{array}{c}644(18.4) \\
1.16(0.70-1.92)\end{array}$ & $\begin{array}{c}643(19.3) \\
1.80(1.02-3.18)^{*}\end{array}$ \\
\hline & $12+$ & $\begin{array}{c}389(11.0) \\
\text { [Reference] }\end{array}$ & $\begin{array}{c}454(13.2) \\
2.01(1.12-3.60)^{*}\end{array}$ & $\begin{array}{c}408(11.7) \\
1.27(0.75-2.16)\end{array}$ & $\begin{array}{c}431(12.3) \\
1.16(0.70-1.94)\end{array}$ & $\begin{array}{c}492(14.8) \\
2.07(1.16-3.67)^{*}\end{array}$ \\
\hline \multicolumn{2}{|c|}{ Psychiatrist review } & $\begin{array}{c}117 \text { (3.3) } \\
\text { [Reference] }\end{array}$ & $\begin{array}{c}130(3.8) \\
1.14(0.88-1.47)\end{array}$ & $\begin{array}{c}138(4.0) \\
1.19(0.92-1.53)\end{array}$ & $\begin{array}{c}135(3.9) \\
1.17(0.91-1.50)\end{array}$ & $\begin{array}{c}128(3.9) \\
1.17(0.90-1.50)\end{array}$ \\
\hline \multicolumn{2}{|c|}{$\begin{array}{l}\text { Other mental health } \\
\text { review }\end{array}$} & $\begin{array}{c}111(3.1) \\
\text { [Reference] }\end{array}$ & $\begin{array}{c}98(2.9) \\
0.91(0.69-1.19)\end{array}$ & $\begin{array}{c}111(3.2) \\
1.03(0.78-1.34)\end{array}$ & $\begin{array}{c}106(3.0) \\
0.97(0.74-1.27)\end{array}$ & $\begin{array}{c}87(2.6) \\
0.84(0.63-1.11)\end{array}$ \\
\hline \multicolumn{2}{|c|}{ 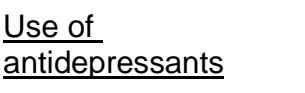 } & $\begin{array}{c}391(11.0) \\
\text { [Reference] }\end{array}$ & $\begin{array}{c}467(13.4) \\
1.26(1.09-1.45)^{\ddagger}\end{array}$ & $\begin{array}{c}463(13.2) \\
1.24(1.07-1.43)^{\ddagger}\end{array}$ & $\begin{array}{c}491(13.9) \\
1.31(1.14-1.51)^{\ddagger}\end{array}$ & $\begin{array}{c}464(13.8) \\
1.30(1.12-1.50)^{\ddagger}\end{array}$ \\
\hline
\end{tabular}

OR $(95 \% \mathrm{Cl})$ : odds ratio (95\% confidence interval of the odds ratio) derived from a multilevel logistic regression model. Note: the OR reported takes into account the exposure of participants' general practitioners to an educational intervention about depression and self-harm behaviour (no/yes).

*Association no longer significant after the analyses were adjusted for prevalent comorbidity.

${ }^{\ddagger}$ The associations did not change substantially when the analyses were adjusted for the presence of clinically significant depressive symptoms at the baseline and the 24-month assessments. 


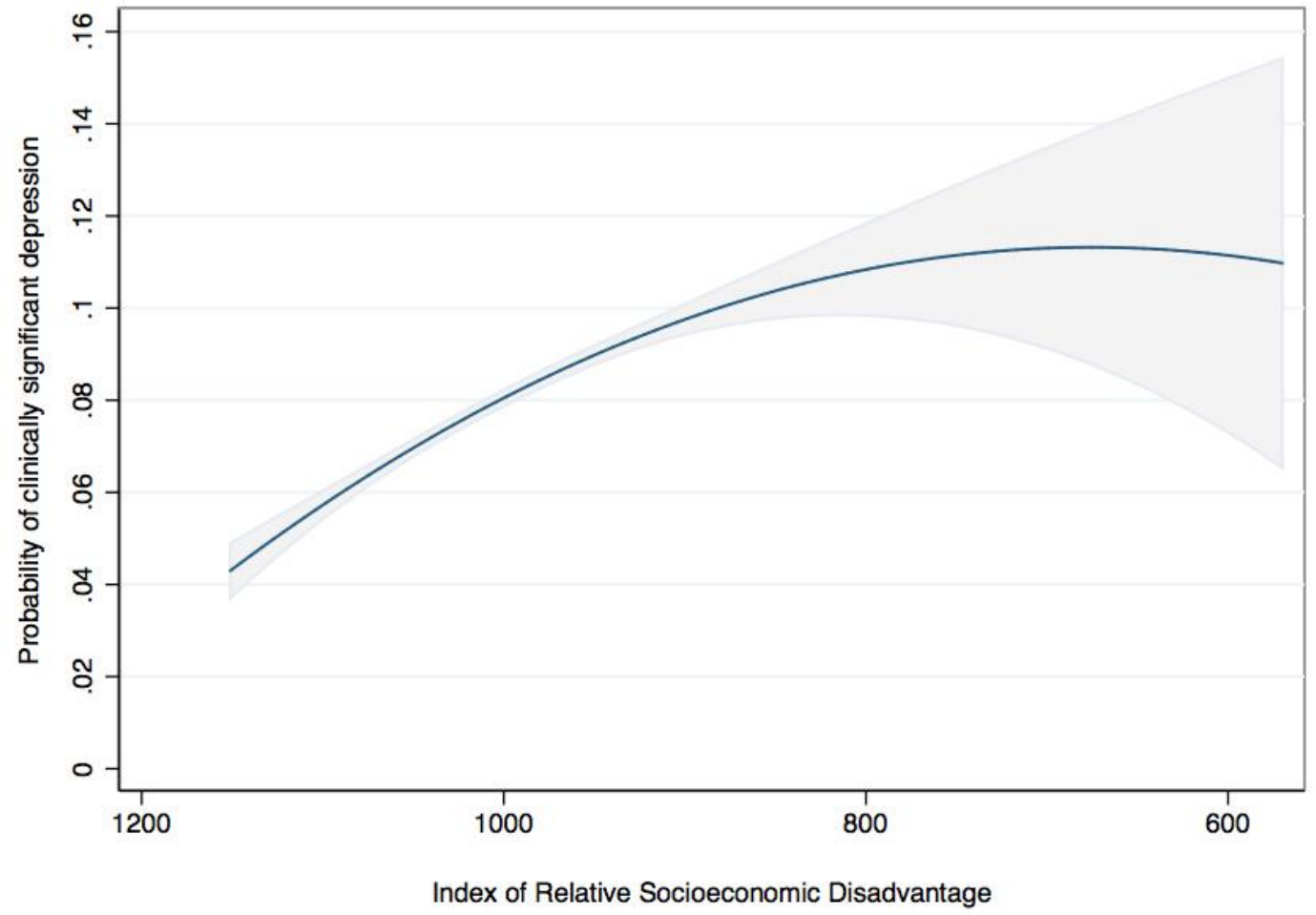

Panel A

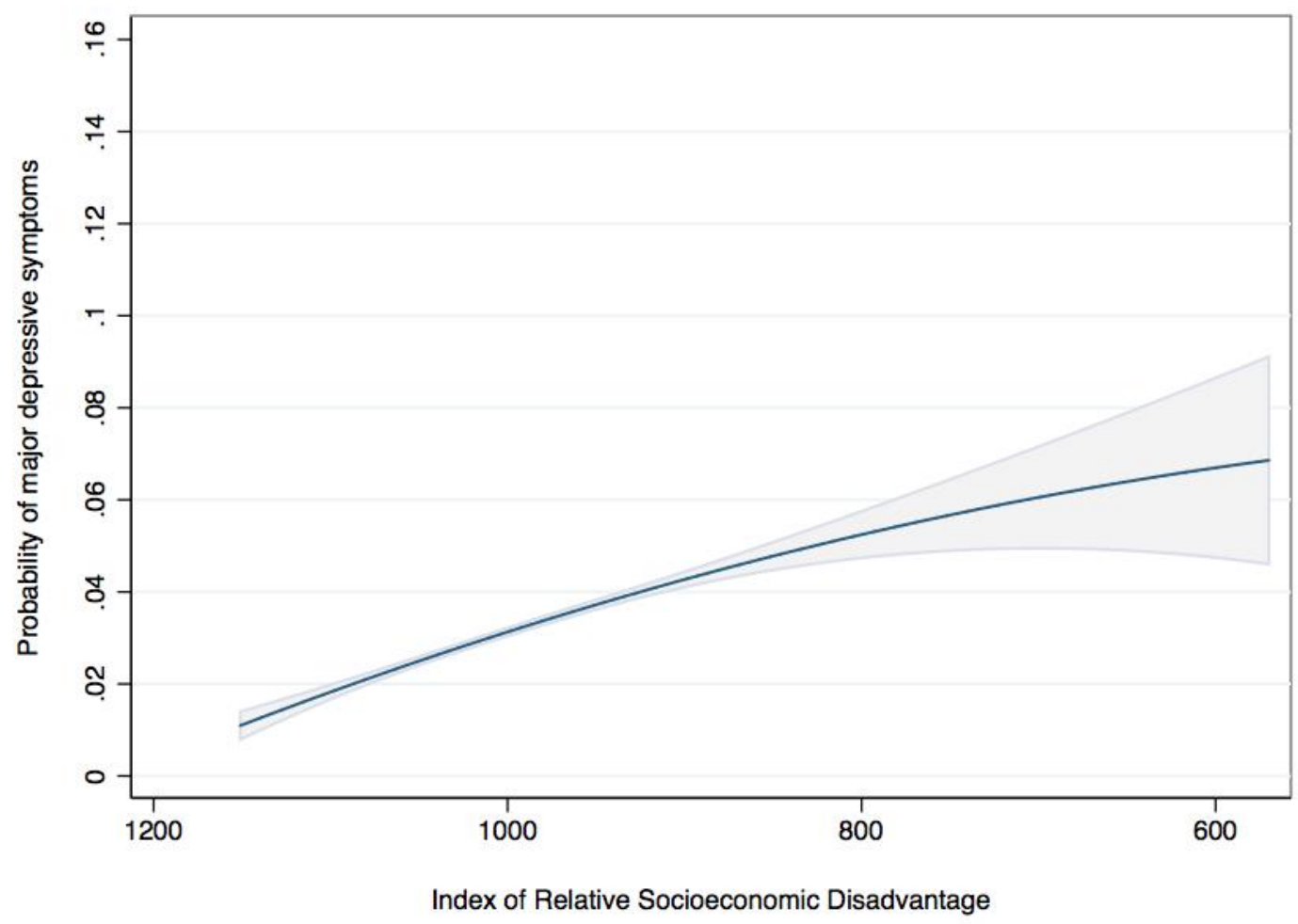

Panel B

Figure 1. The figures show the adjusted probability of depression according to the Index of Relative Socioeconomic Disadvantage (lower scores indicate greater disadvantage). The line indicates the estimated probability and the grey area the $95 \%$ confidence interval of the probability. Panel A displays the probability of clinically significant depressive symptoms and panel B the probability of major depressive symptoms at the time of enrollment into the study. 


\section{University Library}

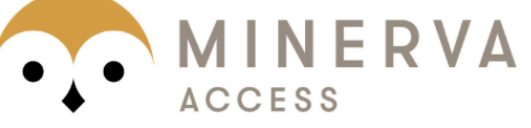

A gateway to Melbourne's research publications

Minerva Access is the Institutional Repository of The University of Melbourne

Author/s:

Almeida, OP;Pirkis, J;Kerse, N;Sim, M;Flicker, L;Snowdon, J;Drapers, B;Byrne,

G;Lautenschlager, NT;Stocks, N;Alfonso, H;Pfaff, JJ

Title:

Socioeconomic disadvantage increases risk of prevalent and persistent depression in later life

Date:

2012-05-01

Citation:

Almeida, O. P., Pirkis, J., Kerse, N., Sim, M., Flicker, L., Snowdon, J., Drapers, B., Byrne, G., Lautenschlager, N. T., Stocks, N., Alfonso, H. \& Pfaff, J. J. (2012). Socioeconomic disadvantage increases risk of prevalent and persistent depression in later life. JOURNAL OF AFFECTIVE DISORDERS, 138 (3), pp.322-331. https://doi.org/10.1016/j.jad.2012.01.021.

Persistent Link:

http://hdl.handle.net/11343/58479 